\title{
Motor Torque Overload Protector Based on CAD/CAE Features of Fixture was used to Optimize
}

\author{
Zhengcheng Zhang ${ }^{1,}$, , Huahui $\mathrm{Yi}^{1, \mathrm{~b}}$ and Jinkui Cao ${ }^{1, \mathrm{c}}$ \\ 1'School of Mechanical Engineering,Xi 'an technology university ,710021,Xi 'an, PRC \\ aZZhangzhengcheng521@163.com, byihh0118@126.com, ‘229388330@qq.com
}

Keywords: CAD/CAE; Solidworks; Function; Characteristics ;The finite element model

\begin{abstract}
Parts of fixture design directly affects the processing quality of parts, especially the torque overload protector parts processing. In this paper, through the design of the function-feature-structure model, based on CAD/CAE common software, through Solid Works three-dimensional modeling software to build the model, and use soliworks simulation module, fixture rigidity analysis, verify reasonable. At the same time, the three-dimensional model of the part is introduced into the finite element software ANSYS to analyze the rigidity of the clamping force to verify whether the clamping fixture design is reasonable and whether the part deformation meets the design requirements.
\end{abstract}

\section{Introduction}

In the development of modern manufacturing industry, the machining process is sophisticated increasingly. As the important part of the mechanical processing system, the rationality of the fixture's design and the manufacturing quality assurance relate with the processing quality of the workpiece.

In the processing of high precision requirements, fine fixture deformation and work piece deformation will affect the work piece machining accuracy. The jig and the work piece are susceptible to local deformation due to the load from the clamping force. This deformation, in many cases due to the load force and the work piece reaction force caused by the imbalance. Although the clamp body is often made of high-strength steel, the deformation caused ${ }^{[1]}$ by the torque difference is small to the micron level that cannot be seen with the naked eye, but because of the high precision machining process on the processing accuracy requirements must be designed to better fixture body, Increase the rigidity of the fixture against deformation.

Torque overload protector, also known as torque limiter, is often used to install between the main and passive sides of the power transmission. When the torque exceeds the set value, the torque limiter will produce separation, thus effectively protecting the drive machinery (such as motors, Reducer, servo motor) and load. The clutch gear clutch, by limiting the force in the transmission system to protect the motor, components and to solve some difficult situations when the torque is greater than the rated value, will produce a slip to protect the structure. In the torque limiter, the clutch gear machining accuracy is particularly important.

According to the problems existing in the fixture design and the function model of the fixture, the feature-structure of the fixture function and structure is proposed, and the design pattern of the function-feature-structure is established. Fixture design of the program. Based on the characteristics of fixture design, especially based on the integration with CAD/CAE, through the use of Solidworks software powerful features, design and analysis according to the actual conditions of the production site to compare the process options to select the appropriate program, fixture design and three-dimensional modeling.[1] Then the simulation and optimization of the fixture clamping and shaping effect were carried out by Ansys finite element analysis software. So that enterprises in the production process to reduce the production cycle, production costs, improve product quality, so as 
to achieve high efficiency.

\section{Decomposition of Functional Characteristics of Fixture and Establishment of Functional Model}

In order to achieve fast, convenient and safe installation of the workpiece, fixture must meet the fixture should meet the positioning stability, positioning uniqueness, clamping stability and the overall constraints of four functional requirements. The fixture is used for milling two slots of $38 \mathrm{~mm}$ width. According to the grading characteristics of fixture in function and structure, the functional structure of machine tool fixture is established by hierarchical decomposition in the concept of machine tool fixture design.[2] Based on the classification of the function and the basic principle of the fixture design, the overall function of the fixture can be divided into positioning function, clamping function, installation function and indexing function, and each function can be subdivided. According to the characteristics of the workpiece processing function, the establishment of functional decomposition unit, as Shown in Fig. 1.[3]

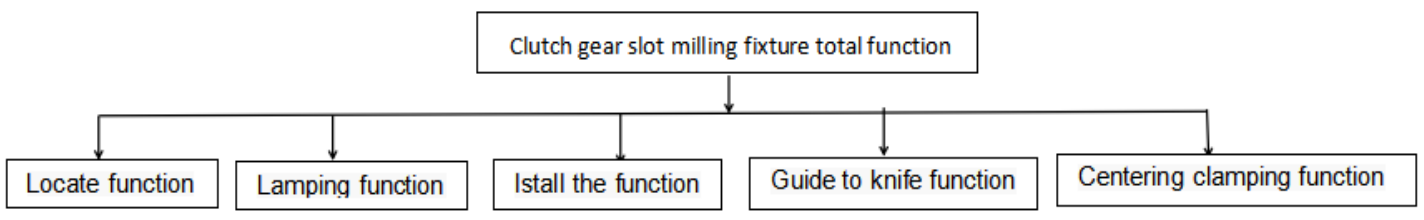

Figure 1. Functional decomposition uni

According to the functional decomposition to further establish the function - feature - structure diagram, shown in Fig. 2.[4]

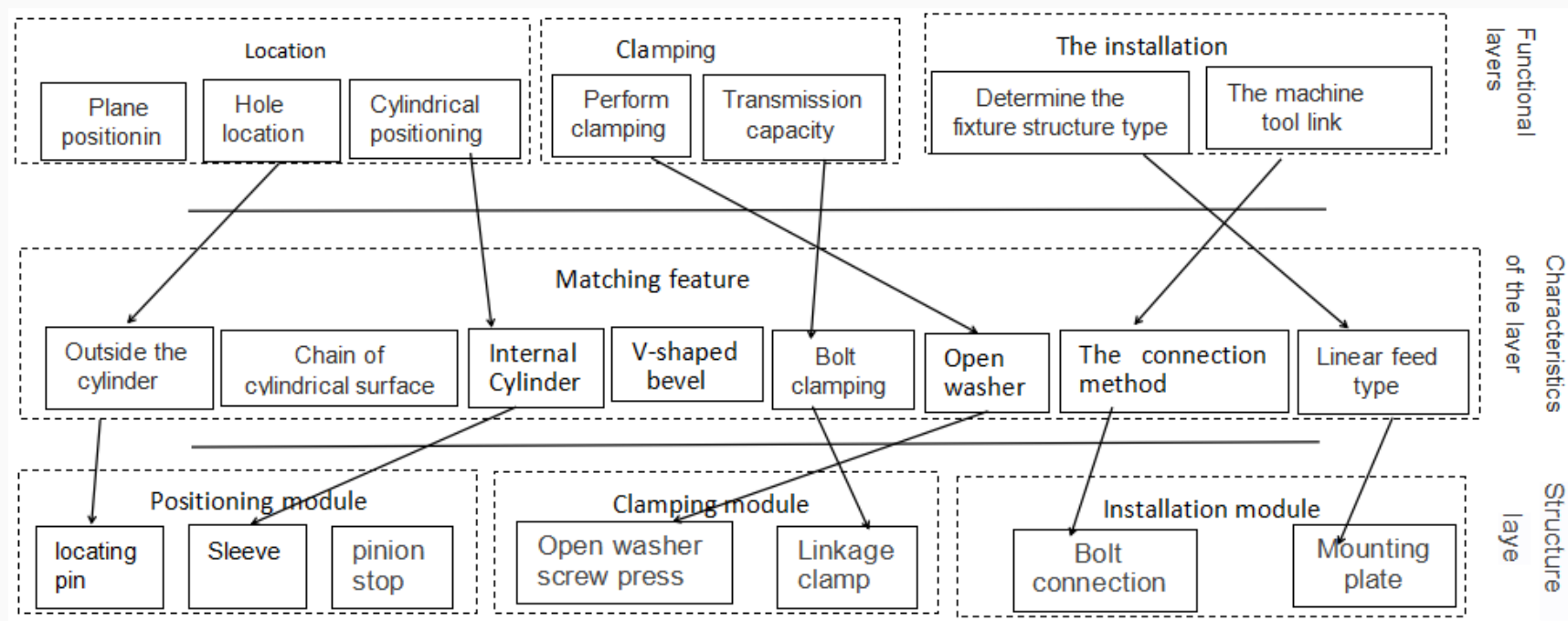

Figure 2.Function-Characteristics-Structure Diagram

\section{Solid Modeling Assembly and Parametric Modeling in Solidworks Environment Based on Model Feature}

The parts need to be milled with two slots of width $38 \mathrm{~mm}$, which play a limited role in the work of the parts and require very high machining precision. In order to ensure the accurate positioning and stability of the workpiece, in the process of designing the fixture, the model is established according to the functional decomposition and the functional model. After the fixture 3D model is generated, the fixture is optimized by the solidworks interference checking and simulation module. In the design process to improve the fixture components of the generalization and standardization, reduce fixture cost in order to improve the design efficiency. 
Dimensional Model. SolidWorks drawing fixture 3D graphics, as shown in Figure 1. The fixture portion includes five sub-modules: a support module, an adjustment module, a detection module, a positioning module and a clamping module.[5]

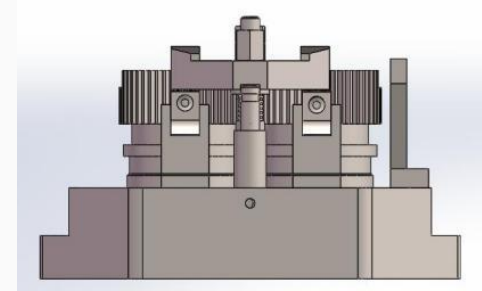

Figure 3.Front view

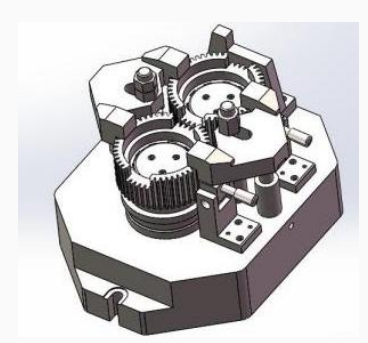

Figure 4.Three-dimensional model

Fixture Optimization Program. Which in the five sub-module, step up the module, positioning module directly affects the accuracy of the fixture to ensure the effectiveness of the parts. By fixture design flow chart in Figure 5, and constantly optimize the fixture to ensure fixture processing reliability.

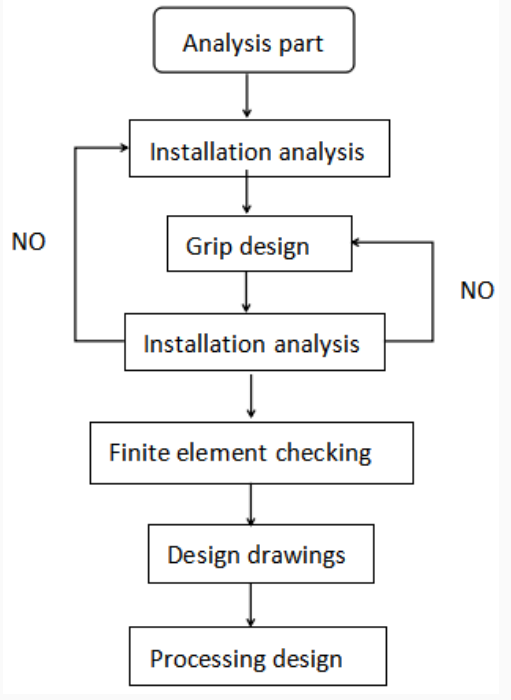

Figure 5.Fixture design flow chart

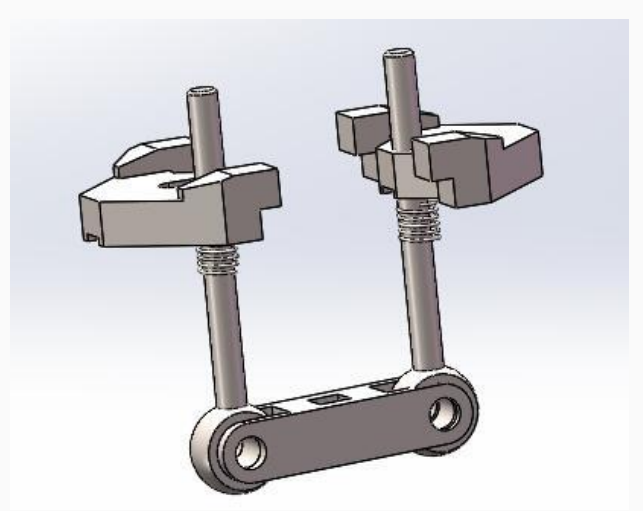

Figure 6.Three Dimensional Modeling of Linkage Plates

Through solidworks interference inspection, simulation module and workpiece stress analysis of the fixture can be optimized, as follows:

(1)The precision of the positioning datum has a direct impact on the tooth profile accuracy, so it is important to ensure that the bore and end faces are selected as the reference for the design basis and the measurement and assembly datum.

(2)To ensure the fixture strength and reliability, through the simulation of the fixture model of the three-dimensional finite element analysis can be obtained in the workpiece can be used to tighten the linkage plate while pressing the workpiece.

Feature-Based Parametric Modeling. Because of the versatility of the clutch gear, parametric modeling for clutch gear fixture design can greatly improve the efficiency, based on this paper about VisualC ++6.0 and SolidWorks together, the clutch gear fixture design parameters were explored specific steps: 


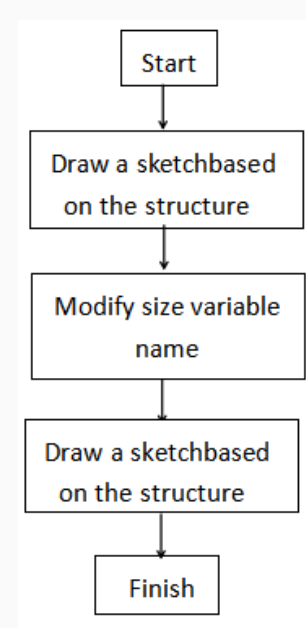

(a))Template creation process

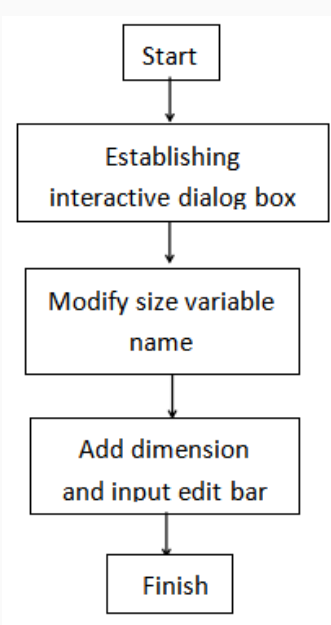

(b) Create a dialog box

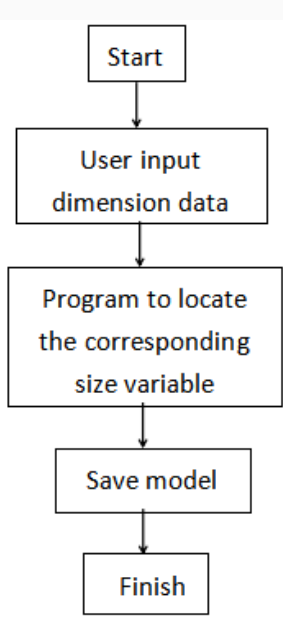

(c)Program running

For the processing of different types of clutch gear clutch design, by comparison with the above model clutch gear, need to change the size of parts of the clip body. From the model library to open the model file, through the dialog box (Figure 5) on the specified size parameters to modify, rebuild, you can get to meet the needs of the model. This method has a small programming effort and has nothing to do with the modeling process. [6]It is suitable for situations where the model is highly standardized or where the modeling process is complicated and the variable parameters are small.

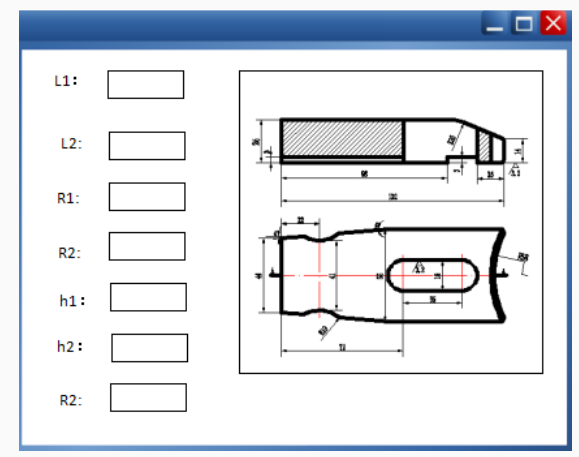

Figure 7.Parametric modeling dialog

\section{Load Stress Analysis and Deformation Distribution Law of Workpiece}

Manufacturing process, the parts stamping manufacturing bias, transport deformation and tooling fixture deviation and so difficult to avoid, resulting in the workpiece clamping force in the workpiece is uneven, affecting processing accuracy. As the parts with high precision requirements $(<0.008 \mathrm{~mm})$, must be part of the clamping force after the check to ensure that the stress of the parts did not exceed the yield stress of the material itself, to avoid damage caused by clamping force parts. SolidWorks was used to create 3D solid parts during the analysis, and the parts were imported into ANSYS12.1 through the already established link port. [7]As shown in figure 5, SolidWorks solid modeling for the part, in order to reduce the amount of computer operations, as long as its part as a representative, the finite element analysis can be. The analysis model is shown in figure 9. 


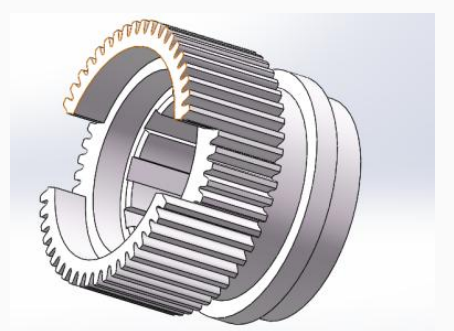

Figure 8.Three-dimensional entity parts

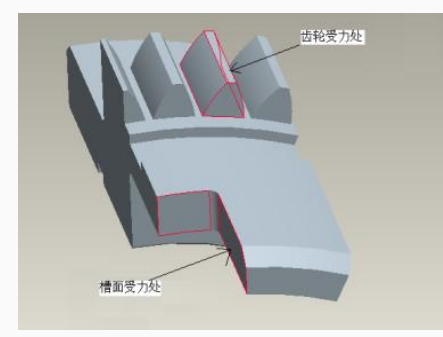

Figure 9. Analysis model

Element Type Setting, Material Parameter Setting and Divide the Grid. ANSYS finite element analysis software with a variety of unit types. In the choice of unit type should consider the complexity of the analysis model, the calculation of the accuracy requirements, the calculation of the economy and other factors to select the appropriate type of unit. In practical engineering problems, the 4-node tetrahedral element with constant strain is more suitable for the calculation. Finite element analysis, for three-dimensional modeling, the hexahedral element can be considered first, because it generates fewer nodes, high precision, and its structural requirements on the part of relatively regular. For clutch gears, taking into account the flexibility and convenience and analysis of the solution time, can be used 10-node tetrahedral element Solid92. When performing static analysis of the workpiece in ANSYS, the elastic modulus of the material needs to be entered, the density of the part to be entered in the modal analysis, and the unit of the part to be able to match the ANSYS analysis software. [8]Entity into the finite element model, the use of free mesh, may be appropriate to improve the division of precision, using four precision divisions, as shown in Figure 10.

Table 1 Parts parameter relational tables

\begin{tabular}{|c|c|c|c|}
\hline Name & Density & Elas tic modulus & Poisson ratio \\
\hline parameter & $7.85 \mathrm{~g} / \mathrm{cm}^{\wedge} 3$ & $210 \mathrm{GPa}$ & 0.31 \\
\hline $\begin{array}{c}\text { ANSYS conversion } \\
\text { value }\end{array}$ & $7.85 \mathrm{e}-9 \mathrm{~kg} / \mathrm{mm}^{\wedge} 3$ & $2.1 \mathrm{e}+5 \mathrm{MPa}$ & 0.31 \\
\hline
\end{tabular}

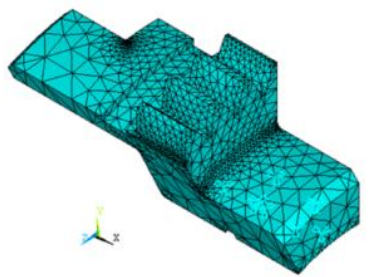

Figure 10.Grid graph

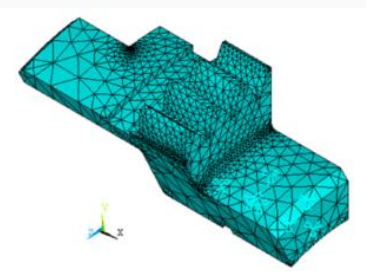

Figure 11.Constraint graph

Applying Constraint and Load. Constraints include movement constraint and rotation constraint on $\mathrm{X}, \mathrm{Y}$ and $\mathrm{Z}$ axes, which are mainly based on model coordinate system. For the workpiece, is fixed by the plate and the base, so the main constraints of the two cutting surface of the $\mathrm{X}$-axis displacement, the right part of the part in the work of the basic state of equilibrium, can be fully constrained. The loads P1, P2 are applied to the parts, as shown in figure 11 .

Solution and Finite Element Analysis. In ANSYS, the results for the solution can be post-processor POST1 and general post-processor POST26 to understand. This analysis only need to use a common post-processor can be. Respectively, to the parts of the displacement and deformation, Von Mises stress diagram, the first principal stress diagram, [9]the second principal stress diagram and the third principal stress diagram. 


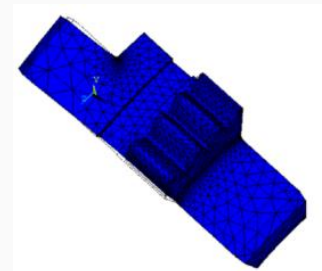

Figure 12.Deformation diagram

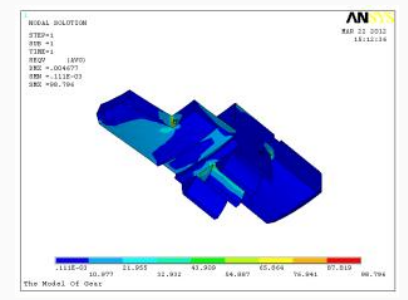

Figure 14.Von mises stress map

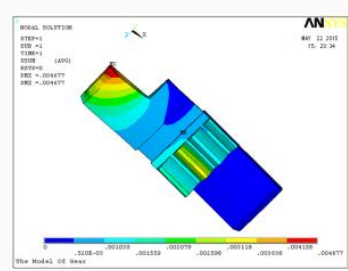

Figure 13.Total displacement cloud graph display

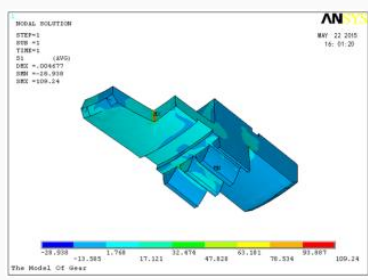

Figure 15.First principal stress

As can be seen from Fig. 14, the maximum Von Mises stress of the part is $98.796 \mathrm{MPa}$, less than the tensile strength $600 \mathrm{MPa}$ and the yield strength $355 \mathrm{MPa}$. As shown in Fig. 15, the maximum compressive stress of the first principal stress is $109.24 \mathrm{MPa}$ and the maximum tensile stress is $28.938 \mathrm{MPa}$, which does not exceed the yield strength of $355 \mathrm{MPa}$.[10]The stress concentration at the groove joint is also the same. As shown in Figure 16, the second principal stress maximum compressive stress of $26.892 \mathrm{Mpa}$, the maximum tensile stress of $31.33 \mathrm{Mpa}$, but also to ensure the safety of parts. As shown in Figure 17, the maximum compressive stress of the third principal stress is $17.81 \mathrm{Mpa}$, the maximum tensile stress is $89.939 \mathrm{Mpa}$, and the tensile stress is the largest.

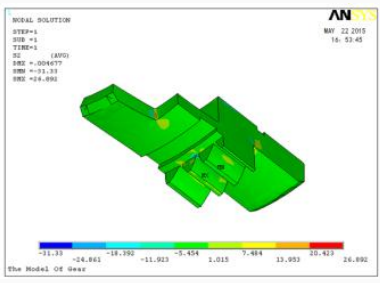

Figure 16.Second principal stress

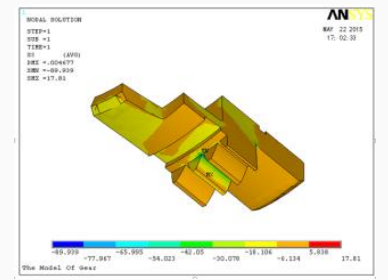

Figure 17.Third principal stress

Analysis of Figure 12 to Figure 17 shows that the clutch gear under the action of the load, the maximum displacement deformation of $0.004677 \mathrm{~mm}$, the end of the groove in the displacement of the largest deformation; Von Mises stress maximum of $98.796 \mathrm{Mpa}$; the three main stress in the maximum Compressive stress is 109.24Mpa; maximum tensile stress is 89.939Mpa; maximum compressive stress and maximum tensile stress are less than the yield strength of $355 \mathrm{Mpa}$ and tensile strength 600Mpa. Therefore, the parts are safe and reliable.

\section{Conclusion}

Fixture design is a very critical part of the fixture design, affecting the follow-up technical design and detailed design. Through the function - feature - structure model, the structure of each sub function is selected, and the structure scheme of the fixture is given. ANSYS software is used to simulate and optimize the clamping and shaping effect of the fixture. The strength of the workpiece is obtained and the safety and effectiveness of the fixture are verified. In the fixture design, before the production, the use of finite element software on the fixture simulation, can not meet the performance requirements of the fixture in time to improve the structure, material until a more optimized design, thereby shortening the design cycle. 


\section{Reference:}

[1] D. Waryg andM.Wochal:Journal of Trandisciplinart SystemsScience, Vol. 16, (2012) No 1, p. 1

[2] 21.

[3] C.A. Liu,Z.H.Yang,Y. Hao,K.Z. Huang,S.X.Wu and F.Z.Sun:Computer Integrated Manufacturing Systems, Vol. 12(2010)No. 8,p.1192.(In Chinese)

[4] Q.L. Lliao, H.p. Wang and G.H. Deng: The methods of mechanical design. Chongqing :( Chongqing University Press, China 2006), p.115.

[5] X.J. Dong: Machine manufacturing and research,Vol.4(2007)No.2.p.26.(In Chinese)

[6] X.H. Wang: Machine tool fixture Atlas:(Machinery Industry Press, China,1992),p.17.

[7] P.P. Zhang,H.Tao, X.F.Gu:Modern manufacturing engineering, Vol. 9(2006)No.9,p.62.

[8] D.H. Liu,C.J. Zhao and Y.X. Zhang: Journal of Engineering Design, Vol. 17(2010) No. 3,p.190.

[9] X.W. Yang:3D CAD/CAE Software Environment Reliability Analysis and Design of Mechanical Products(MS.,Central South University, China 2013),p.52.(In Chinese)

[10] Y.L. Wang:Value Engineering,Vol.2(2014)NO.3,p.203.(In Chinese)

[11]L.B. Zhang:Element analusis of large vacuum steel spherical tank based on ANSYS(MS., Northestern University,China 2014),p25.(In Chinese) 